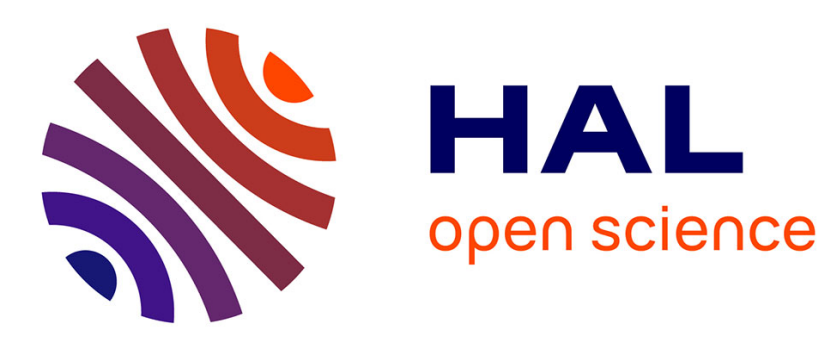

\title{
Propagation Experiment at Ka-Band in French Guiana: First Year of Measurements
}

\author{
Xavier Boulanger, Bouchra Benammar, Laurent Castanet
}

\section{To cite this version:}

Xavier Boulanger, Bouchra Benammar, Laurent Castanet. Propagation Experiment at Ka-Band in French Guiana: First Year of Measurements. IEEE Antennas and Wireless Propagation Letters, 2019, 18 (2), pp.241-244. 10.1109/lawp.2018.2887280 . hal-02046470

\section{HAL Id: hal-02046470 https://hal.science/hal-02046470}

Submitted on 22 Feb 2019

HAL is a multi-disciplinary open access archive for the deposit and dissemination of scientific research documents, whether they are published or not. The documents may come from teaching and research institutions in France or abroad, or from public or private research centers.
L'archive ouverte pluridisciplinaire HAL, est destinée au dépôt et à la diffusion de documents scientifiques de niveau recherche, publiés ou non, émanant des établissements d'enseignement et de recherche français ou étrangers, des laboratoires publics ou privés. 


\title{
Propagation Experiment at Ka-Band in French Guiana: First Year of Measurements
}

\author{
Xavier Boulanger, Bouchra Benammar and Laurent Castanet
}

\begin{abstract}
ONERA, the French Aerospace Lab, and CNES, the French Space Agency, are currently running a Ka-band propagation experiment at the Guiana Space Centre (CSG) in Kourou (French Guiana). A rain gauge and a beacon receiver able to record the $20.2 \mathrm{GHz}$ beacon signal of the Amazonas 3 satellite have been deployed. The equipment is operational since January 1, 2017 and the duration of the experiment has been set to 3 years.

This letter addresses some results of the first year of measurements (from January 2017 to December 2017). The annual and monthly Complementary Cumulative Distribution Functions of rainfall rate and rain attenuation are presented as well as a comparison with the rain attenuation prediction method recommended in ITU-R P.618-13.
\end{abstract}

Index Terms-Equatorial area, Ka-Band, Measurements, Propagation, Satellite communications.

\section{INTRODUCTION}

$\mathrm{W}$ ITH the increasing demand on High Throughput Satellite (HTS) services, there has been a steady move towards using higher frequencies namely the $\mathrm{Ka}$ band (20 $\mathrm{GHz}-30 \mathrm{GHz}$ ) as well as Q/V bands $40 \mathrm{GHz}-50 \mathrm{GHz}$ for their higher available bandwidth. However, these frequencies suffer from increased signal attenuation when propagating through the atmosphere. These effects are all the more significant in tropical and equatorial areas due to more adverse weather conditions. Thus in order to better design future telecommunication payloads using EHF frequencies covering tropical and equatorial areas, a thorough study of the propagation impairments needs to be carried out to evaluate the distributions of the static (power margins) and dynamic (fade/interfade durations, site diversity, ...) characteristics of Earth-Space communications at these high frequencies.

To this end, ONERA and the French Ministry of Defence (MoD) designed, at the beginning of the $\mathrm{XXI}^{\text {st }}$ century, a

Manuscript received September 17, 2018; revised November 29, 2018; accepted December 11, 2018. Date of publication MMMMM DD, 2018; date of current version MMMMM DD, 2018. (Corresponding author: Xavier Boulanger)

X. Boulanger and Laurent Castanet are with ONERA / DEMR, Université de Toulouse, F-31055 Toulouse, France (e-mail: Xavier.Boulanger@onera.fr, Laurent.Castanet@onera.fr).

B. Benammar is with CNES DSO/RF/ITP, F-31400 Toulouse, France (email: Bouchra.Benammar@cnes.fr).

Color versions of one or more of the figures in this communication are available online at http://ieeexplore.ieee.org.

Digital Object Identifier ZZZZZ propagation experiment to be held in French Guiana with the 20 and $40 \mathrm{GHz}$ beacons of the satellite STENTOR [1]. Unfortunately, due to the loss of the satellite during its launch, other opportunities have been investigated to study Earthspace propagation in equatorial areas. Since 2015, ONERA and CNES have been conducting a Ka-band propagation campaign over India in collaboration with ISRO, the Indian Space Agency, using the $20 \mathrm{GHz}$ and $30 \mathrm{GHz}$ beacons of the GSAT-14 satellite [2], back-up of the original GSAT-4 satellite [3]. On the other hand, Joanneum Research has been conducting a Ka band propagation experiment in two sites in Malaysia under ESA/ESTEC contract using the $20 \mathrm{GHz}$ beacon of the French Syracuse-3A satellite [4]. Finally, since the end of 2017, CNES and ONERA have been conducting a Ka-band propagation experiment in French Guiana using the 20.2 GHz beacon signal of the Amazonas-3 satellite.

Section II of this letter describes the main characteristics of this Ka-band propagation experiment and setup. Some details of the space and ground segments are provided and a short description of the data processing procedures is given. Section III addresses the statistical analyses of rainfall rate and rain attenuation at $20.2 \mathrm{GHz}$ for which annual and monthly Complementary Cumulative Distribution Functions of rainfall rate and rain attenuation are presented. Finally, a brief comparison of the results with the rain attenuation prediction method recommended in ITU-R P.618-13 is highlighted.

\section{DESCRIPTION OF THE PROPAGATION EXPERIMENT}

\section{A. Space Segment}

Amazonas 3, launched into space on February 7, 2013, is a HISPASAT satellite located on the geostationary orbit at $61^{\circ} \mathrm{W}$ of longitude [5]. A Ka-band beacon signal is available on-board. The exact carrier frequency is $20.1995 \mathrm{GHz}$ with a Right-Hand Circular Polarization (RHCP). The beacon EIRP does not seem to be publically available. Starting from a link budget analysis and the experimental assessment of the dynamic range, it has been roughly estimated to be around 20 dBW.

\section{B. Ground Segment}

In December 2016, a CNES Ka-band beacon receiver and a rain gauge have been deployed at the Technical Centre of the Guiana Space Centre (CSG) in Kourou (French Guiana). The exact latitude and longitude of the Amazonas 3 propagation experiment are $5.1713^{\circ} \mathrm{N}$ and $-52.6862^{\circ} \mathrm{E}$, respectively (see Fig. 1). The climate normals in Kourou, computed over the 
period 1981-2010, are the following [6]: the mean number of rainy days is 190.96 days/year and the mean rainfall amount is $2838.4 \mathrm{~mm} /$ year. The precipitations are not homogeneously distributed all over the months and are marked by two rainy seasons (from April to June and from December to January) and a dry season (from August to October). The driest month is September with $32.8 \mathrm{~mm}$ of precipitation and the wettest month is May with $503.2 \mathrm{~mm}$ of precipitation.

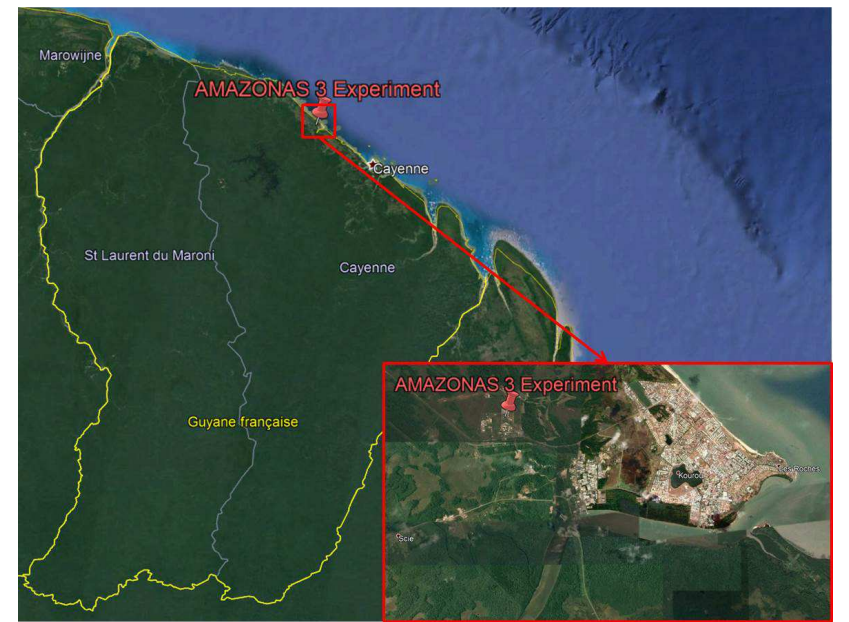

Fig. 1. Overview of the measurement site.

The rain gauge (see Fig. 2) is a corrosion resistant dualchamber tipping bucket rain gauge able to record the exact instant of tips (1 second resolution). The main technical characteristics are the following:

- collecting area of $316 \mathrm{~cm}^{2}$

- $0.1 \mathrm{~mm}$ per pulse resolution

- $0.015 \mathrm{~mm}$ accuracy

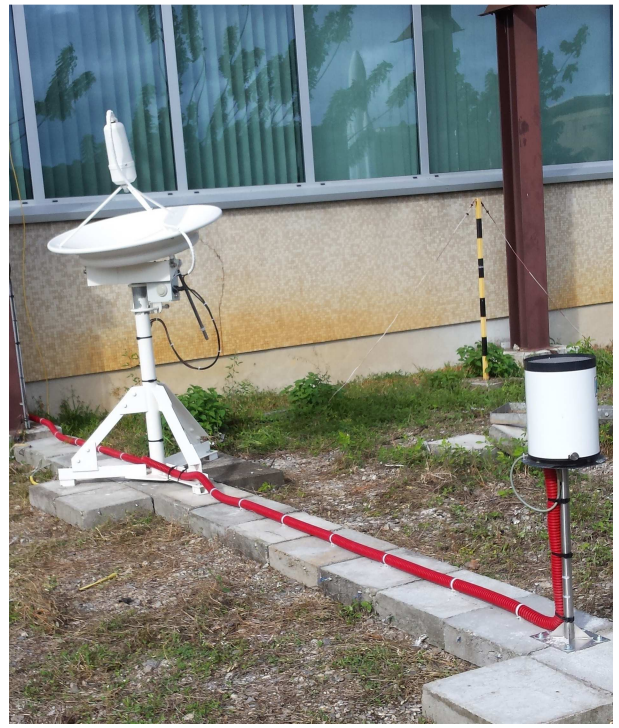

Fig. 2. Overview of the equipment.

The beacon receiver (see Fig. 2) has similar characteristics than the receiver deployed in Salon de Provence during the French Ka-band site diversity propagation experiment [7]. Basically, it is composed of a $0.9 \mathrm{~m}$ prime focus parabolic antenna with a commercial thermally stabilized Ka-band to L- band Low Noise Block-Converter (linear polarization) performing the down-conversion from $20.2 \mathrm{GHz}$ to L-band. Some adjustments have been added to the external parts of the receiver in order to be more resilient to humid outdoor conditions (anti-rust specific painting and sealing of the electronic boxes). Then, a specifically designed softwarecontrolled L-band to $5 \mathrm{MHz}$ board is used. In this way, the design is easily reusable for different experiments between 19.7 GHz and 20.2 GHz. Finally, the signal is digitized and processed with a frequency search and tracking algorithm to be able to integrate the signal power over a very small frequency bandwidth (typically $50 \mathrm{~Hz}$ ). It has to be noticed that the receiver is linearly polarized while the polarization of the beacon is RHCP, so a $3 \mathrm{~dB}$ loss must be added in the link budget. The clear-sky Signal-to-Noise Ratio (SNR) has then been roughly estimated to be around $34 \mathrm{~dB}$ for a $50 \mathrm{~Hz}$ integration bandwidth. By fixing the SNR detection threshold to $10 \mathrm{~dB}$, the dynamic range of measurements has been experimentally assessed to reach around $24 \mathrm{~dB}$. The receiver is recording data at $10 \mathrm{~Hz}$ sampling rate.

Due to the antenna design and the high elevation angle, water can accumulate inside the main reflector resulting in wetting effect on the measurements. To prevent it, a water discharge hole has been drilled. It enables most of the water to be immediately drained out.

Both the beacon receiver and the rain gauge are operational since January 1,2017 . The elevation and azimuth angles are $78.49^{\circ}$ and $238.36^{\circ}$ respectively for pointing the Amazonas 3 satellite.

\section{Data Processing}

The objective of data processing is to extract validated concurrent rain attenuation and rain fall rate time series.

The rain gauge data (tips) are converted into rainfall rate measurements (in $\mathrm{mm} / \mathrm{h}$ ) according to the methodology described in [8].
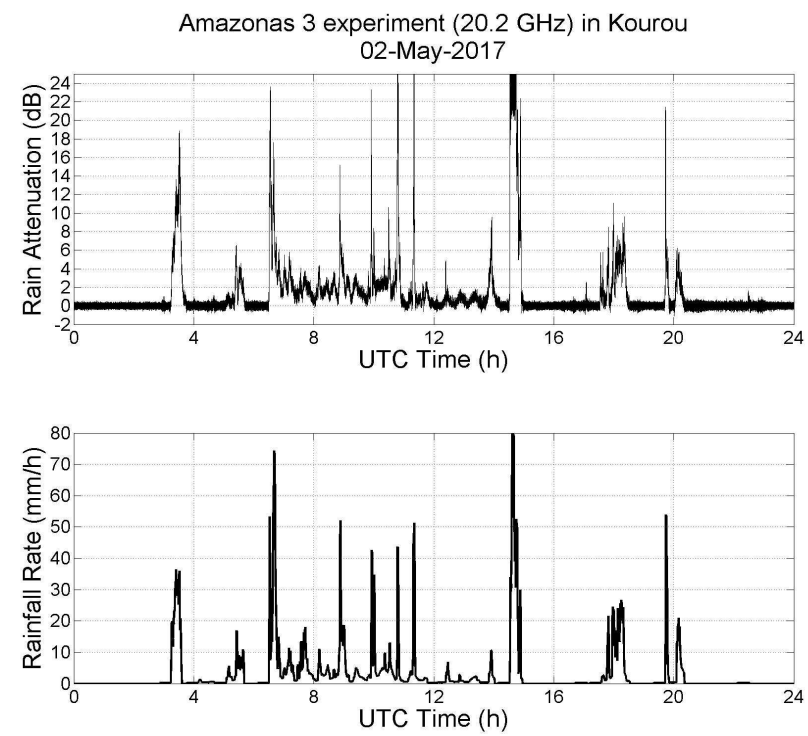

Fig. 3. Example of processed rain attenuation and rainfall rate time series (May 2, 2017). 
Beacon data processing consists in extracting a reference level to be subtracted from the original signal power level time series to obtain the desired excess attenuation time series (rain attenuation including a part of cloud attenuation when it is raining) [9]. The signal level is first low-pass filtered (raisedcosine filter with $0.025 \mathrm{~Hz}$ cut-off frequency) in order to remove tropospheric scintillation. Then, when a rain event is detected, this reference level is linearly interpolated. One of the main characteristics of this propagation experiment is that the elevation angle is very high $\left(78.49^{\circ}\right)$. Consequently, there is a very strong correlation between signal fading and rainfall rate measurements. So, the event detection method is based on the use of the concurrent rainfall rate time series. Finally, the beginning and the end of each rain attenuation event are manually adjusted. An example of processed rain attenuation and rainfall rate time series over one full day (May 2, 2017) is shown in Fig. 3.

\section{STATISTICAL ANALYSES}

One full year (January 2017 - December 2017) of data has been processed. Daily rainfall rate and rain attenuation time series have been produced and statistical analyses have been performed. The availabilities of valid data coming from the rain gauge and from the beacon receiver are $99.75 \%$ and $99.65 \%$, respectively. The availability of strictly concurrent valid data coming from both the rain gauge and the beacon receiver is $99.58 \%$.

The collected annual rainfall amount is $3085.1 \mathrm{~mm}$. May 2017 was the wettest month with $685.2 \mathrm{~mm}$ and August was the driest month with only $9.3 \mathrm{~mm}$. Note that a record of precipitation has been set in December with $614.7 \mathrm{~mm}$ of precipitation which is more than twice the climate normals [6].

Fig. 4 shows the Complementary Cumulative Distribution Functions (CCDF) of strictly concurrent rainfall rate and rain attenuation at $20.2 \mathrm{GHz}$. It is worth noting that the dynamic range of the beacon receiver is reached for probabilities of exceedance below $0.1 \%$.

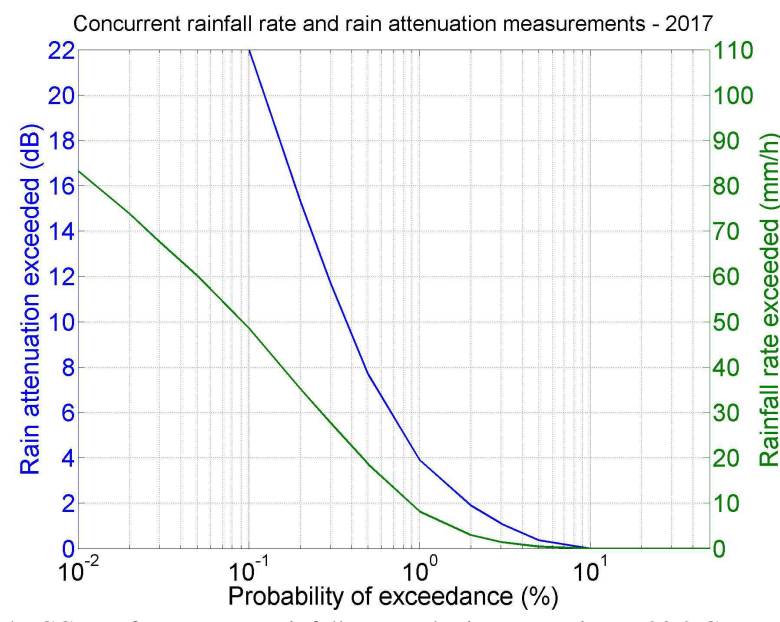

Fig. 4. CCDF of concurrent rainfall rate and rain attenuation at $20.2 \mathrm{GHz}$.

Fig. 5 and Fig. 6 show the monthly CCDF of rainfall rate and rain attenuation at $20.2 \mathrm{GHz}$, respectively. A large monthto-month variability can be noticed and corroborates the presence of the two rainy seasons (from April to May and in
December), and the dry season (from August to September). The rainfall rate values exceeded for $0.01 \%$ (namely $\mathrm{R}_{0.01}$ ) range from $23.9 \mathrm{~mm} / \mathrm{h}$ to $95.4 \mathrm{~mm} / \mathrm{h}$. The experimental value of $\mathrm{R}_{0.01}$ calculated over the full year of measurements is equal to $85.1 \mathrm{~mm} / \mathrm{h}$. For information, the value of $\mathrm{R}_{0.01}$ predicted by ITU-R P.837-7 [10] is equal to $102.1 \mathrm{~mm} / \mathrm{h}$.

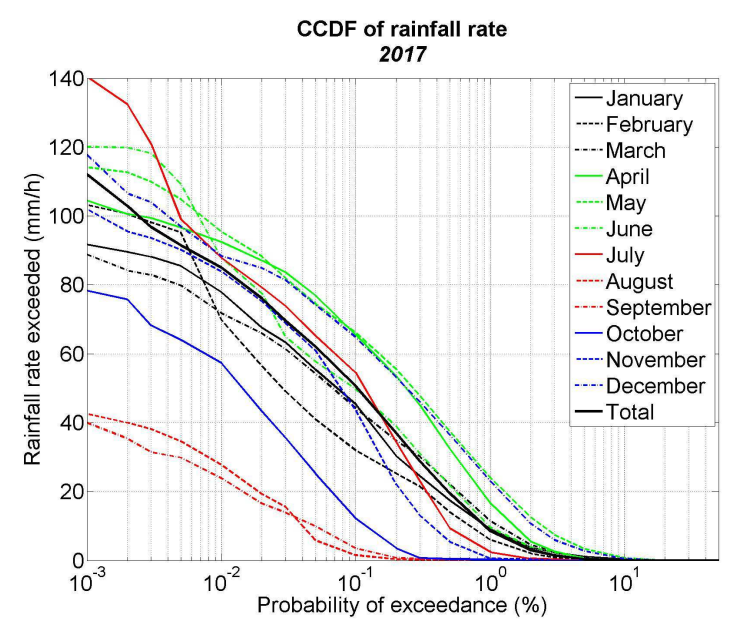

Fig. 5. Monthly CCDFs of rainfall rate.

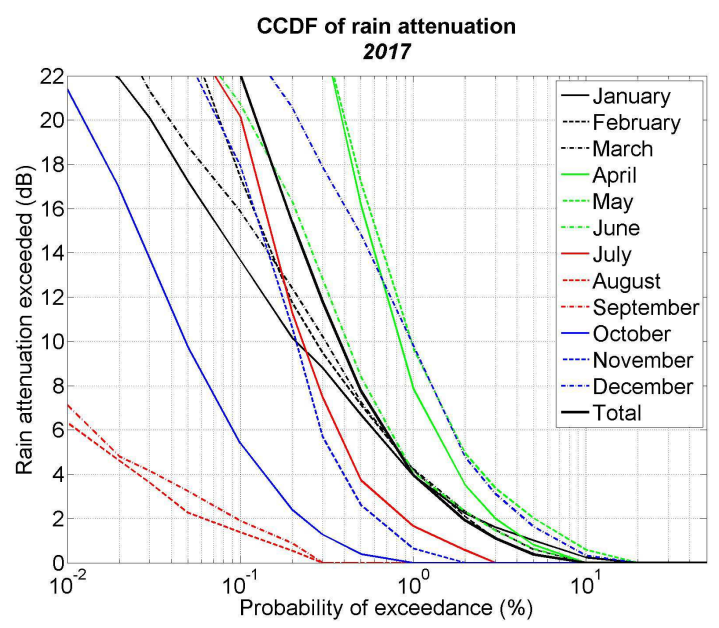

Fig. 6. Monthly CCDFs of rain attenuation at $20.2 \mathrm{GHz}$.

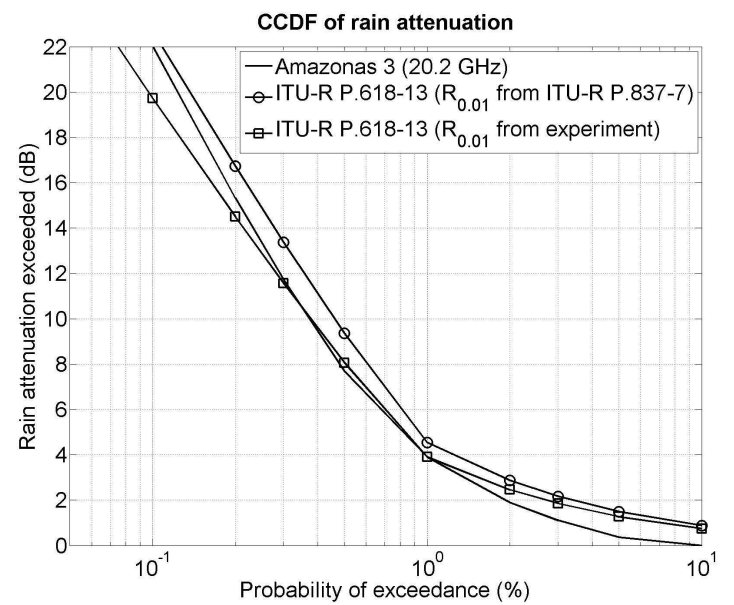

Fig. 7. Comparison of CCDF of rain attenuation with Recommendation ITUR P.618-13. 
Finally, a brief comparison with the rain attenuation statistics prediction method of Recommendation ITU-R P.61813 [11] has been performed. Both the value of $R_{0.01}$ predicted by ITU-R P.837-7 $(102.1 \mathrm{~mm} / \mathrm{h})$ and the experimental one $(85.1 \mathrm{~mm} / \mathrm{h})$ have been used as inputs of the rain attenuation prediction method. The results are highlighted in Fig. 7 where a fair agreement can be noticed especially when using the experimental value of $\mathrm{R}_{0.01}$.

Noting the very unfavorable propagation conditions in Kourou, it tends to prove the burning issue of using Ka-band for satellite communications systems in equatorial areas without adequate Propagation Impairment Mitigation Techniques (PIMT).

\section{CONCLUSION}

ONERA and CNES are currently running a Ka-band propagation experiment at the Guiana Space Centre (CSG) in Kourou (French Guiana) with a rain gauge and a beacon receiver able to record the $20.2 \mathrm{GHz}$ beacon signal of the Amazonas 3 satellite. This letter has presented some results of the first year of measurements (from January 2017 to December 2017) and preliminary comparisons with ITU-R recommendations. Statistical analyses have been performed and annual and monthly $\mathrm{CCDF}$ of rainfall rate and rain attenuation have been presented. A large month-to-month variability has been noticed. It has also been shown that there is a very good agreement of the results with the rain attenuation prediction method recommended in ITU-R P.61813.

For frequencies above $20 \mathrm{GHz}$, gaseous attenuation becomes non-negligible. This is particularly the case in equatorial areas for which the water vapour quantity is very high. This is why, at the beginning of 2018, a GNSS receiver has been installed in order to estimate the integrated water vapour content from the zenith tropospheric delay (ZTD) [12]. It will be very useful to assess the water vapour attenuation during the Ka-band propagation experiment [12], which duration is planned to be at least 3 years.

Future work will address further propagation analyses such as inter-annual variability of excess attenuation and comparisons with Rec. ITU-R P.678-3, as well as statistics of fade dynamics (fade slope, fade duration, time diversity) and tropospheric scintillation.

\section{ACKNOWLEDGMENT}

This work has been carried out under ONERA internal funding and under CNES R\&T study R-S15/TC-0005-066 "Ka-Band Propagation Experiment in French Guiana".

The authors are very grateful to Alexia Lapierre, Coline Morel, Ingrid Epailly, and Christophe Ostapek for their excellent on-site support.

\section{REFERENCES}

[1] J. Lemorton, L. Castanet, V. Huot, and T. Marsault, "A new opportunity for EHF propagation experiments : the EXPRESS campaign with the satellite STENTOR," Int. J. Sat. Com., Vol. 19, May-June 2001, pp. 347-362.
[2] L. Castanet, X. Boulanger, J. Lemorton, and B. Benammar, "Characterisation of the propagation channel at $\mathrm{Ka}$ and $\mathrm{Q} / \mathrm{V}$ bands for satellite communication and Earth Observation systems", $12^{\text {th }}$ European Conference on Antennas and Propagation (EUCAP), London, United Kingdom, April 2018.

[3] K. S. Dasgupta, A. Charania, A. Shukla, R. Acharya, K. Bandyopadhyay, L. Castanet, J. Lemorton, G. Carrie, F. Lacoste, J. P. Taisant, F. Carvalho, " A new propagation campaign in tropical areas: the Ka-band Propagation experiment over India with the GSAT-4 satellite," $3^{\text {rd }}$ European Conference on Antennas and Propagation (EUCAP), Berlin, Germany, March 2009.

[4] F. Cuervo, H. Y. Lam, J. B. Din, J. R. Castro, M. Schmidt and M. Schönhuber, "The Joanneum Research SatCom Ka and Q band campaigns in Europe and Malaysia," $11^{\text {th }}$ European Conference on Antennas and Propagation (EUCAP), Paris, 2017, pp. 1476-1480.

[5] https://www.hispasat.com/en/satellite-fleet/amazonas-3

[6] http://www.meteofrance.com/climat/outremer/kourou/97304003/norma $\underline{\text { les }}$

[7] X. Boulanger et al., "Small and large scale site diversity experiment at Ka-band in the south of France," Int. J. Satell. Commun. Network. 2018; 36:14-28. https://doi.org/10.1002/sat.1190.

[8] ITU-R SG3, Working Party 3M, "On the processing of tipping bucket rain gauge data for study group 3 experimental database," Revision 1 to Fascicle 3M/FAS/8, October 2017

[9] X. Boulanger et al., "Four Years of Total Attenuation Statistics of Earth-Space Propagation Experiments at Ka-Band in Toulouse," IEEE Trans. Ant. Prop., vol. 63, no. 5, pp.2203-2214, May 2015.

[10] ITU-R Recommendations P.837-7, "Characteristics of precipitation for propagation modelling," Geneva, June 2017.

[11] ITU-R Recommendations P.618-13, "Propagation data and prediction methods required for the design of Earth-space telecommunication systems," Geneva, December 2017.

[12] G. Siles, J.M. Riera and P. Garcia-del-Pino, "An Application of IGS Zenith Tropospheric Delay Data to Propagation Studies: Validation of Radiometric Atmospheric Attenuation," IEEE Trans. Ant. Prop., vol.64, no.1, pp.262-270, Jan. 2016. 